\title{
Comparison of a Low Osmolarity Nonionic Radiographic Contrast Agent With a Standard Medium on Renal Function in Cyanotic and Normal Dogs
}

\author{
Ara K. Pridjian, MD, Edward L. Bove, MD, Robert H. Beekman III, MD, \\ and Flavian M. Lupinetti, MD
}

\begin{abstract}
Renal dysfunction may follow administration of lodinated radiographic contrast agents. This complication may be less common when low osmolarity nonionic agents are used. Although potential benefits from the use of low osmolarity nonionic contrast may be minimal in individuals with normal physiology, a greater benefit has been postulated in the presence of chronic cyanosis. To test this hypothesis, six adult mongrel dogs underwent anastomosis of the inferior vena cava to the left atrium. This produced chronic cyanosis with a mean $\mathrm{pO}_{2}$ of $48 \pm 4 \mathrm{~mm} \mathrm{Hg}$ and polycythemia with a mean hematocrit of $56 \pm 2 \mathrm{gm} \%$. Three to 5 months after preparation, these cyanotic dogs and five control dogs each received diatrizoate (a high osmolarity ionic agent) or ioversol (a low osmolarity nonionic agent), $465 \mathrm{mg}$ iodine/ $\mathrm{kg}$ body weight, by intravenous bolus injection. One month later, each animal received the other agent. The order of administration was randomized. Renal function studies, including serum creatinine and creatinine clearance, were performed precontrast, after $60 \mathrm{~min}$, and $24 \mathrm{hr}$ postcontrast. Neither agent adversely affected renal function in either the cyanotic or the normal group. We conclude that at the doses that are commonly used in clinical practice, high osmolarity ionic contrast agents do not create a greater risk of renal injuiry than do low osmolarity nonionic agents in this model of cyanosis. (c) 1994 Wiley-Liss, Inc.
\end{abstract}

Key words: contrast media, diatrizoate, ioversol, creatinine clearance

\section{INTRODUCTION}

Infants with congenital heart disease are subjected to angiocardiography to define their cardiac anatomy. Renal dysfunction often develps in patients with cyanotic congenital heart disease $[1,2]$ and these patients may be predisposed to renal injury from intravenous contrast agents. While low osmolarity nonionic agents are thought to produce less renal injury than high osmolarity ionic agents, the incidence of clinically important renal impairment following injection of either type of contrast agent is low. This low frequency makes it difficult to demonstrate any advantage to the use of expensive low osmolarity nonionic agents in a general population of patients undergoing angiography [3]. Patients with cyanosis, however, are particularly at risk of renal cortical injury following contrast administration, possibly because of polycythemia, oxygen desaturation, or intrinsic renal disease [4]. In cyanotic individuals, therefore, any advantage provided by a low osmolarity nonionic agent may be more pronounced. This study tested the hypothesis that low osmolarity nonionic contrast agents reduce the risk of renal dysfunction in the presence of chronic cyanosis in a canine model.

\section{MATERIALS AND METHODS}

Adult mongrel dogs that had been fasted overnight were anesthetized with sodium pentobarbitol, intubated, and mechanically ventilated. Cefazolin, $25 \mathrm{mg} / \mathrm{kg}$, was given by intramuscular injection. All procedures were performed under sterile conditions in a veterinary operating room. A right anterolateral thoracotomy was performed via the sixth intercostal space. Animals were heparinized $(100 \mathrm{mg} / \mathrm{kg})$ and the inferior vena cava was divided and anastomosed to the left atrium in an end-toside fashion using running 5-0 polypropelene. The thoracotomy was closed and animals were allowed to re-

From the Departments of Pediatric Cardiolgy and Surgery, Section of Thoracic Surgery, University of Michigan Medical Center, Ann Arbor.

Received June 21, 1993; revision accepted August 30, 1993.

Ara K. Pridian, M.D., is now at Ochsner Clinic Department of Cardiovascular Surgery, 1514 Jefferson Highway, New Orleans, LA 70121. Address reprint requests there.

This work was supported in part by Nallinckrodt Medical, Inc., St. Louis, MO. 
cover for 3 to 5 months. At that time, the mean $\mathrm{pO}_{2}$ among the dogs was $48 \pm 4 \mathrm{~mm} \mathrm{Hg}$ and the mean hemtocrit was $56 \pm 2 \mathrm{gm} \%$.

Experimental observations were performed on six chronically cyanotic dogs and five control animals. Animals were fasted on the day of the study but allowed water ad libitum. Animals received pentobarbitol anesthesia and were intubated for mechanical ventilation. A Foley catheter was inserted into the bladder, a central venous catheter was passed into the internal jugular vein, and an arterial catheter was placed in the femoral artery for blood pressure monitoring and to obtain blood samples. One hour urine collections were obtained for measurements of urine volume and creatinine content. Creatine clearance was calculated from the following formula:

$$
\mathrm{C}_{\mathrm{Cr}}=\mathrm{U}_{\mathrm{Cr}} \times \mathrm{V} / \mathrm{P}_{\mathrm{Cr}}
$$

where $\mathrm{C}_{\mathrm{Cr}}=$ creatinine clearance, $\mathrm{U}_{\mathrm{Cr}}=$ urinary creatine concentration, $\mathrm{V}=$ urine volume, and $\mathrm{P}_{\mathrm{Cr}}=$ plasma creatine concentration. A Kodak Ektachen DT60 analyzer was used with a single slide system to determine serum and urine creatinine.

Each animal then received diatrizoate (a high osmolarity ionic agent) or ioversol (a low osmolarity nonionic agent), $465 \mathrm{mg}$ iodine $/ \mathrm{kg}$ body weight by intravenous bolus injection. Blood and urine samples were then obtained 1 hour after contrast administration. All instrumentation was removed, and the animals were allowed to awaken and return to their cages, where food and water were provided ad libitum. One additional blood sample was obtained 24 hours after administration of the contrast medium for measurement of serum creatinine. One month later, each animal underwent the same procedure but with administration of the other contrast medium. The order of contrast administration was randomized.

Group means and standard errors were calculated for each group of dogs receiving each contrast agent. Statistical analysis was performed using paired Student's t test to compare differences in response to the contrast agents within groups and unpaired Student's $t$ test to compare the cyanotic and normal groups. Differences were considered statistically significant at a $p$ value $<$ .05 .

Animals received humane care in compliance with the "Principles of Laboratory Animal Care" formulated by the National Society for Medical Research and the "Guide for the Care and Use of Laboratory Animals" prepared by the Institute of Laboratory Animal Resources and published by the National Institutes of Health (NIH Publication No. 86-23, revised 1985).
TABLE I. Comparisons Between Normal and Cyanotic Animals (Mean values \pm standard error of the mean)

\begin{tabular}{lcc}
\hline & Normal & Cyanotic \\
\hline Weight $(\mathrm{kg})$ & $44 \pm 3$ & $43 \pm 2$ \\
$\mathrm{pO}_{2}$ (mm Hg) & $85 \pm 5$ & $48 \pm 4^{*}$ \\
Hematocrit (\%) & $34 \pm 2$ & $56 \pm 2^{*}$ \\
Baseline serum creatinine $(\mathrm{mg} / \mathrm{dl})$ & $0.76 \pm 0.05$ & $0.78 \pm 0.15$ \\
Baseline creatinine clearance $(\mathrm{ml} / \mathrm{min})$ & $46 \pm 10$ & $43 \pm 3$ \\
\hline
\end{tabular}

${ }^{*} p<.05$ compared to normal group.

\section{RESULTS}

Comparisons between the cyanotic and acyanotic animals are shown in Table I. Cyanotic animals were significantly different from control animals with respect to $\mathrm{pO}_{2}$ and hematocrit. Renal function was similar, however. Responses to contrast administration are illustrated in Figures 1 and 2. Serum creatinine fell significantly in the cyanotic group 1 hour after the administration of either contrast agent. By $24 \mathrm{hr}$ after contrast, serum creatinine returned to baseline levels. Creatinine cleareance 1 hour after injection of either agent did not decrease in the cyanotic or in the control group.

\section{DISCUSSION}

Conventional high osmolarity ionic contrast media are composed of organic molecules of triiodobenzoic acid. Each molecule contains three iodine atoms and dissociates into two osmotically active particles in solution. The typical osmolarity range is from 1,400 to $2,400 \mathrm{mOsm} / 1$. Low osmolarity nonionic agents also have three atoms of iodine per molecule, but they do not dissociate. The osmolarity of these agents is $400-850 \mathrm{mOsm} / 1$, or about one-third of the high osmolarity ionic agents [5]. Low osmolarity nonionic agents are well tolerated, less painful, and produce equal density on angiograms compared to ionic agents. Low osmolarity nonionic agents, however, are more expensive than high osmolarity ionic media. It has been estimated that the increased incremental cost of low osmolarity nonionic agents is $\$ 100-200$ per catheterization. In the United States, approximately $1,000,000$ procedures are performed annually. Thus, the uniform use of low osmolarity nonionic contrast would add $\$ 100,000,000$ to $\$ 200,000,000$ to the nation's health care costs [6].

Adverse effects of contrast media include pulmonary edema, consumption coagulopathy, myocardial ischemia and infarction, ventricular arrytrhmias, bradycardia and asystolic cardiac arrest, cerebral edema and convulsions, glottic edema with airway obstruction, laryngeal spasm, spinal cord necrosis, and renal cortical necrosis $[6,7]$. Renal insufficiency may also occur after contrast administration. Factors that may be important in predicting 


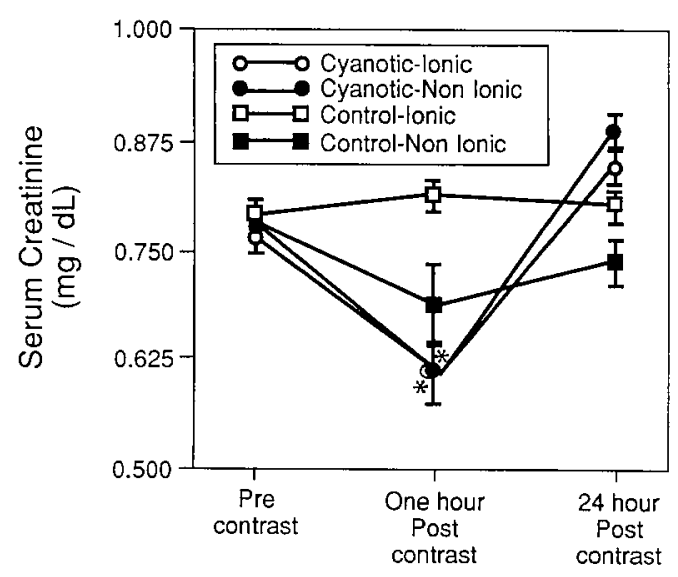

Fig. 1. Serum creatinine before and after contrast injection in control and cyanotic animals. Serum creatinine was decreased in cyanotic animals $1 \mathrm{hr}$ postcontrast with either contrast agent, and returned to baseline by $24 \mathrm{hr}\left({ }^{*} p<.05\right.$ vs. precontrast control).

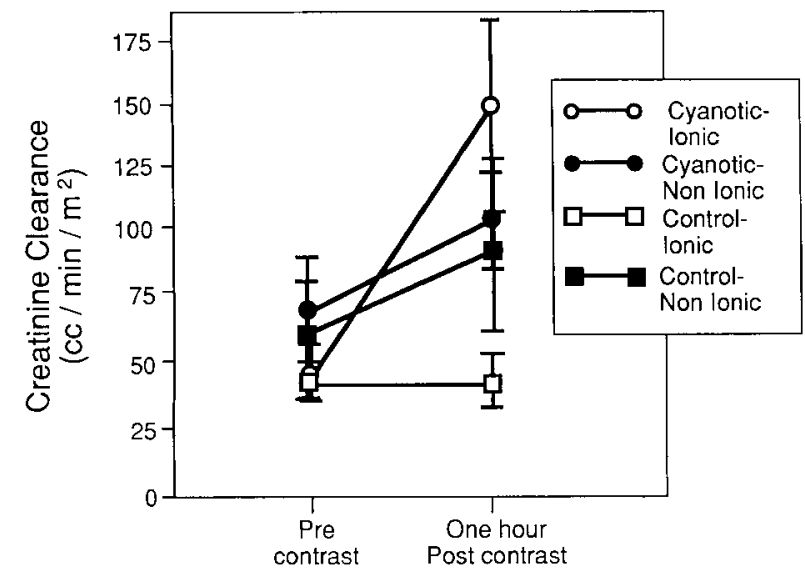

Fig. 2. Creatinine clearance before and after contrast injection in control and cyanotic animals. Creatinine clearance did not decrease in cyanotic or normal dogs after receiving either ionic or nonionic agents.

renal insufficiency after contrast administration include diabetes, multiple myeloma, volume depletion, and preexisting renal insufficiency $[8,9]$. In such individuals there is up to a $30 \%$ risk of an increase in serum creatinine of more than $20 \%$. Without these risk factors, however, renal dysfunction occurs in only $2 \%$ of patients and is usually transient [10].

Few clinical or laboratory studies have been performed to identify and stratify contrast-related risks in patients undergoing angiography for congenital cardiac disease. Sagy and associates [10] studied two groups of patients with congenital heart disease to determine the response to contrast agents. One group of patients had a preponderance of left ventricular volume overload, which were mostly due to ventricular septal defects or other left-to-right shunt lesions. The other group consisted of patients with obstruction to right ventricular outflow, such as pulmonary stenosis or tetralogy of Fallot. The left ventricular volume overload group exhibited a significant elevation of serum creaatinine and uric acid in the first 24 hours after contrast injection. This renal impairment appeared to be related to age, with patients older than 5 years exhibiting the greatest rise in creatinine [11].

Effective precautions to reduce the frequency and severity of contrast-induced renal insufficiency remain a desirable objective. If it could be demonstrated that low osmolarity nonionic contrast agents were efficacious in this regard, even in a selected group of patients, a stronger argument could be made for their application. Although low osmolarity nonionic media have theoretical advantages in reducing adverse effects, most clinical trials have not supported their use [3,12-15]. In a retrospective analysis of patients at high risk for renal insufficiency because of preexisting kidney disease, administration of low osmolarity medium was associated with a $15 \%$ incidence of further renal impairment, and the resulting nephropathy correlated significantly with the amount of contrast that was administered [16]. The dose of contrast medium administered in this study was equivalent to a $2 \mathrm{ml} / \mathrm{kg}$ bolus, within the $1-3 \mathrm{ml} / \mathrm{kg}$ range of contrast dosing currently used at this institution.

Some clinical studies, however, have found some benefits of low osmolar nonionic media. Gertz and associates found iopamidol, a low osmolar nonionic agent, to be associated with less nausea and vomiting, allergic reaction, and adverse effects of all types compared with ioxaglate, a high osmolar ionic contrast [17]. The study reported by Jenvnikar and colleagues found low osmolarity nonionic solutions to be associated with a decreased risk of renal impairment as assessed by sensitive measurement of urinary tubular enzyme excretion. In this study, however, glomerular filtration rate was not affected, so the clinical importance of the enzymuria was judged to be uncertain [4].

Because the additional expense may not justify the routine administration of low osmolarity nonionic agents to all patients, identification of patients at a particularly high risk for contrast-related complications may lead to more rational use. Cyanotic patients may represent such a high risk group. Adults with cyanotic congenital heart defects have urinary abnormalities consistent with glomerulopathy in as many as a third of cases [4]. Renal insufficiency associated with cyanosis correlates with the degree of polycythemia [1] as well as the duration of cyanosis [2]. Evaluation of the renal effects of contrast media is therefore warranted in this group of patients. The small number of animals used in this study may limit the ability of this investigation to discern subtle differ- 
ences. The absence of any detectable renal impairment, however, at contrast doses consistent with those used in typical angiographic examinations does not support the use of low osmolarity nonionic media in the presence of chronic cyanosis. This study examined only one of the multiple risks of contrast administration, and it remains possible that low osmolarity nonionic media do provide some degree of protection against hemodynamic complications in cyanotic individuals.

Although there seem to be fewer adverse effects of nonionic than ionic agents, large clinical trials do not conclusively show their advantage. Because of the additional expense of nonionic agents, it may become difficult to justify their use in all patients, and it may become necessary to select patients who are at highest risk and would benefit most from use of nonionic agents $[7,8]$. While this study involves only a small number of animals and does not address other adverse effects, it suggests that patients with cyanotic congenital heart disease and polycythemia are not necessarily at high risk for developing acute renal failure when receiving ionic contrast agents.

\section{ACKNOWLEDGMENTS}

The authors are grateful to Kathleen Moser, Research Department, and to Carol Varma, Lehigh Valley Hospital, for editorial assistance, manuscript preparation, and computer graphics.

\section{REFERENCES}

1. Passwell T, Orda S. Modan M, Shem-Tov A, Aladjem M, Boichis $\mathrm{H}$ : Abnormal renal functions in cyanotic congenital heart disease. Arch Dis Child 51:803-805, 1976.

2. Aperia A, Bjarke B, Broberger $O$, Thoren $C$ : Renal function in Fallot's tetralogy. Acta Paediatr Scand 63:398-404, 1974.

3. Harding MB, Davidson DJ, Pieper KS, Hlatky M, Schwab SJ, Morris KG, Hermiller JB, Bashore TM: Comparison of cardiovascular and renal toxicity after cardiac catheterization using a nonionic versus ionic radiographic contrast agent. Am J Cardiol 68:1117-1119, 1991

4. Flanagan M, Hourihan M, Keane JF: Incidence of renal dysfunction in adults with cyanotic congenital heart disease. Am J Cardiol 68:403-406, 1991 .
5. Ritchie JL, Nissen SE, Douglas JS, Jr, Dreifus LS, Gibbons RJ, Higgins CB, Schelbert HR, Seward JB, Zaret BL: Use of nonionic or low osmolar contrast agents in cardiovascular procedures. J Am Coll Cardiol 21:269-273, 1991.

6. Lalli AF: Contrast media reactions: data analysis and hypothesis. Radiology 134:1-12, 1980.

7. Rich MW, Crecelius CA: Incidence, risk factors, and clinical course of acute renal insufficiency after cardiac catherization in patients 70 years of age or older: a prospective study. Arch Intern Med 150:1237-1242, 1990.

8. Taliercio CP, Vliestra RE, Ilstrup DM, Burnett JC, Menke KK, Stensrud SL, Holmes DR, Jr: A randomized comparison of the nephrotoxicity of iopamidol and diatrizoate in high risk patients undergoing cardiac angiography. J Am Coll Cardiol 17:384-390. 1991.

9. Bakal CW, Haramati N, Friedman AC, Lautin JL, Braha S, Kadish EG, Sprayregen S: Radiocontrast-associated renal dysfunction: incidence and risk factors. AJR Am J Roentgenol 157:48$58,1991$.

10. Sagy M, Aladjem M, Shem-Tov A, Wshkol A, Orda S, Hegesh $\mathrm{J}$, Boichis $\mathrm{H}$ : The renal effects of radiocontrast administration during cardioangiography in two different groups with congenital heart disease. Eur J Pediatr 141:236-239, 1984.

11. Barrett BJ, Pargrey PS, Vavasour HM, O'Dea FO, Kent G, Stome E: A comparison of nonionic, low-osmolality radiocontrast agents with ionic, high-osmolality agents during cardiac catheterization. N Engl J Med 326:431-436, 1992.

12. Steinberg EP, Moore RD, Powe NR, Gopalan R, Davidoff AJ, Litt M, Graziano S, Brinker JA: Safety and cost effectiveness of high-osmolaity as compared with low-osmolality contrast material in patients undergoing cardiac angiography. $\mathrm{N}$ Engl $\mathrm{J}$ Med 326:425-430, 1992.

13. Schwab SJ, Hlatky MA, Pieper KS, Davidson CJ, Morris KG, Skelton TM, Bashore TM: Contrast nephrotoxicity: a randomized controlled trial of a nonionic and ionic radiographic contrast agent. N Engl J Med 320:149-153, 1989.

14. Hlatky MA, Morris KG, Peiper KS, Davidson CJ, Schwab SJ, Bashore TA: Randomized comparison of the cost and effectiveness of iopamidol and diatrizoate as contrast agents for cardiac angiography. J Am Coll Cardiol 4:871-877, 1990.

15. Taliercio CP, McCallister SH, Holmes DR, Ilstrup DM, Bliestra RE: Nephrotoxicity of nonionic contrast media after cardiac aniography. Am J Cardiol 64:815-816, 1989.

16. Gertz EW, Wisneski JA, Miller R, Knudtson M, Robb J, Dragatakis L, Browne KF Jr, Vetrovec G, Smith SC, Jr: Adverse reactions of low osmolality contrast media during cardiac angiography: a prospective randomized multicenter study. J Am Coll Cardiol 19:899-906, 1992.

17. Jevnikar AM, Finnie KJ, Dennis B, Plummer DT, Avila A, Linton AL: Nephrotoxicity of high and low osmolality contrast media. Nephron 48:300-305, 1988. 